\title{
Проектирование и расчет автономных фотоэлектрических энергетических установок
}

\author{
О. Пчельникова-Гротова ${ }^{1}$
}

УДК 620.4:621.311.25:620.92 | ВАК 05.11.07

\begin{abstract}
Возобновляемые источники энергии (ВИЭ) обладают значительными экологическими и социальными преимуществами по сравнению с традиционными, в первую очередь, потому, что при их работе отсутствуют отходы и вредные выбросы в окружающую среду. Отрасль быстро развивается, появляются новые виды солнечных батарей, растет их КПд. По данным Bloomberg, за последние шесть лет энергия солнечных батарей подешевела на 80\% [1]; стоимость самих установок в последнее десятилетие резко снижается, так что на фоне высоких цен на ископаемое топливо экономическая эффективность солнечной генерации постоянно возрастает, особенно для удаленных и труднодоступных районов. В последнем случае имеет значение также тот факт, что автономные топливные электростанции производят энергию сравнительно низкого качества, что дополнительно увеличивает конкурентоспособность энергоустановок на возобновляемых источниках энергии.
\end{abstract}

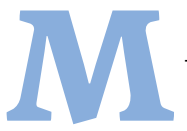
етодическое обеспечение расчетов энергетических установок на базе ВИЭ содержит информационную и расчетную составляющие. Для фотоэлектрических устройств к первой составляющей относятся данные о ресурсе солнечной радиации. Получить их можно, обратившись к базам данных NASA, Meteonorm и другим источникам, содержащим информацию о количестве солнечного излучения, падающего на горизонтальную приемную площадку определенного размера. Эта информация представляет собой обобщение многолетних наблюдений за климатическими и гелиоэнергетическими характеристиками в тысячах географических локаций по всему миру $[2,3]$.

Вторая составляющая представляет собой расчет параметров автономной электростанции и выбор комплектующих элементов: фотоэлектрических панелей, контроллера, инвертора, аккумуляторных батарей и др. В этой статье приведены последовательность и формулы для такого расчета, инвариантные по отношению к количеству излучения, поступающего на солнечные панели. Понятно, что при оптимальном расположении панелей относительно направления на Солнце количество принимаемой ими энергии существенно возрастает; вопросы построения системы управления ориентацией

МАИ (НИу), к.т.н., доцент, grotova@mail.ru. солнечных панелей будут рассмотрены в следующих публикациях автора по данной тематике.

Типовая структурная схема фотоэлектрической системы автономного электроснабжения приведена на рис. 1.

Определение технических параметров агрегатов энергетической установки на базе солнечных батарей проводится в следующем порядке.

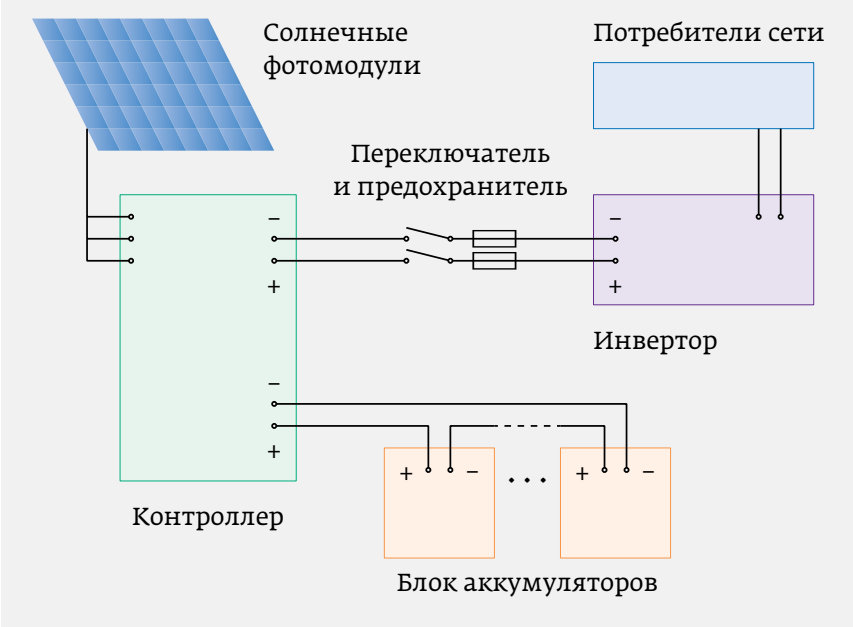

Рис. 1. Структурная схема автономной системы электроснабжения на базе фотоэлектрических преобразователей с аккумуляторным резервом 


\section{1. ВЫБОР ИНВЕРТОРА}

Поскольку фотоэлектрические панели могут вырабатывать только постоянный ток, а бо́льшая часть нагрузки обычно питается переменным напряжением (220 B), то необходимым компонентом солнечной станции является инвертор [4].

Основными параметрами выбора инвертора являются выходная мощность и входное напряжение. Специально рассчитывать инвертор на пиковую мощность нагрузки (максимальная нагрузка с учетом пусковых мощностей приборов) не требуется, она обычно компенсируется способностью инвертора в течение короткого времени отдавать мощность, превышающую паспортное значение. Последнее рекомендуется выбирать с небольшим, не более 10\%, запасом, так как избыток мощности инвертора влечет за собой неоправданное увеличение потерь энергии при питании приборов нагрузки и потребления инвертора на "холостом ходу».

Так как инвертор в составе станции запитывается от солнечных панелей или от аккумуляторов, для расчета параметров этих агрегатов необходимо знать входную потребляемую - мощность инвертора, которая превышает потребную выходную мощность на величину его собственных внутренних потерь. Их уровень для современных инверторов можно принять равным 10\% от паспортной выходной мощности прибора.

Исходя из сказанного, входная мощность инвертора $P_{\text {инв }}$ определяется как

$$
P_{\text {инв }}=P_{\text {потр }} \cdot k \text {, }
$$

где $\mathrm{P}_{\text {потр }}$ - номинальная мощность нагрузки, равная 2530\% мощности одновременно включенных приборов, Вт; k-коэффициент, учитывающий запас по мощности и собственные потери в инверторе, его рекомендуемая величина $k=1,2$.

При выборе входного напряжения $U_{\text {инв }}$ нужно иметь в виду, что с увеличением $\mathrm{P}_{\text {инв }}$ растут входные токи и, соответственно, потери на соединительных проводах. Выбор более высокого входного напряжения из стандартного ряда 12, 24, 48 В позволяет снизить эти потери. Кроме того, следует учитывать целый ряд параметров, которые определяются видом нагрузки и условиями эксплуатации:

- сигнал на выходе (чистая синусоида или модифицированная синусоида);

- способ преобразования энергии (низкочастотный или высокочастотный);

- возможность параллельного подключения (масштабирования);

- наличие принудительного охлаждения;

- малое потребление на холостом ходу и наличие спящего режима;
- наличие и характеристики защиты от высокого и низкого напряжения блока аккумуляторов, от короткого замыкания и перегрузки по выходу, от перегрева;

- рабочий диапазон температур.

\section{2. ВЫБОР МОДЕЛИ И КОЛИЧЕСТВА АККУМУЛЯТОРНЫХ БАТАРЕЙ}

Для бесперебойного снабжения потребителей при недостатке энергии, вырабатываемой солнечными панелями (в темное время суток или в пасмурную погоду), обязательным компонентом солнечной электростанции являются аккумуляторные батареи (АКБ), которые служат для накопления электроэнергии и отдачи ее при необходимости потребителю. Именно суммарной емкостью аккумуляторных батарей определяется максимальное время автономной работы солнечной электростанции время резервирования. Ресурс солнечной энергии определяется погодными условиями, зависящими от широты местности, где расположена фотоэлектрическая установка; соответственно, время резервирования характеризуется параметром $\mathrm{N}_{\text {бс }}$ - числом последовательных "дней без солнца", значения которого выбираются из табл. 1.

Суммарная требуемая емкость блока аккумуляторов (БА), обеспечивающая необходимое время резервирования, определяется по формуле

$$
q_{\text {БА }}=\frac{\left(P_{\text {инв }} \cdot N_{6 с} \cdot \alpha\right)}{\left(U_{\text {инв }} \cdot \gamma\right)}
$$

где $q_{\text {БА }}$ - суммарная требуемая емкость, А-ч; $\alpha$ - температурный коэффициент емкости АКБ; $\gamma$ - коэффициент, учитывающий допустимую глубину разряда АКБ (в дальнейшем - коэффициент разряда).

Эти два коэффициента имеют большое значение для выбора типа аккумуляторной батареи, поскольку

Таблица 1. Количество дней без солнца, обусловленное погодными условиями

\begin{tabular}{lccc}
$\begin{array}{l}\text { широта } \\
\text { местности } \\
\text { град.с.ш. }\end{array}$ & $\begin{array}{c}\text { Петние } \\
\text { месяцы }\end{array}$ & $\begin{array}{c}\text { осенние } \\
\text { иесенние } \\
\text { месяцы }\end{array}$ & $\begin{array}{c}\text { зимние } \\
\text { месяцы }\end{array}$ \\
\hline 30 & $2-4$ & $3-4$ & $4-6$ \\
\hline 40 & $2-4$ & $4-6$ & $6-10$ \\
\hline 50 & $2-4$ & $6-8$ & $10-15$ \\
\hline 60 & $3-5$ & $8-12$ & $15-25$ \\
\hline 70 & $3-5$ & $12-14$ & $20-35$ \\
\hline
\end{tabular}




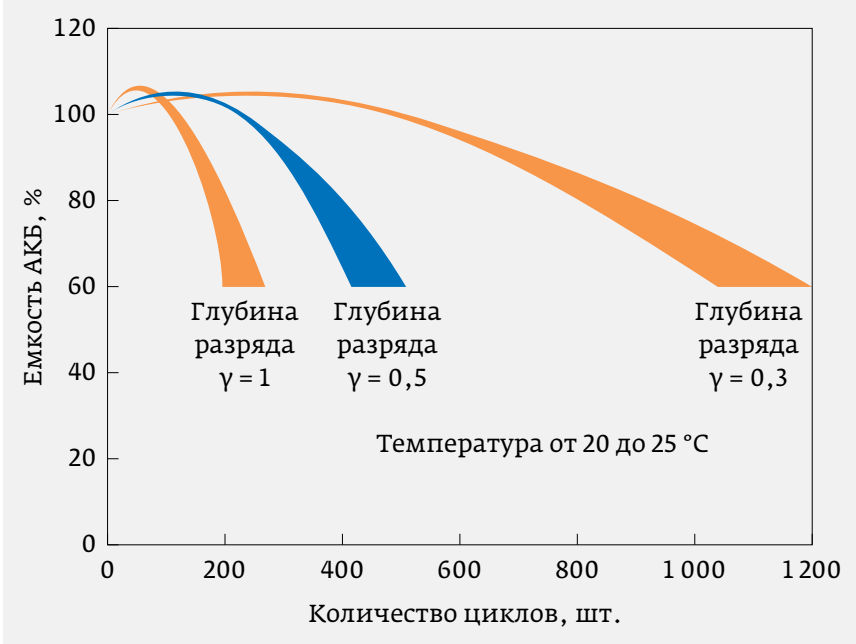

Рис. 2. Скорость падения остаточной емкости АКБ в зависимости от глубины разряда

ими определяется не только расчетная емкость БА, но и темпы падения этого параметра в ходе эксплуатации - по мере роста количества циклов заряда-разряда, - а также общий срок службы батарей [5], что особенно актуально для необслуживаемых (герметичных) АКБ, применяемых в автономных системах энергоснабжения.

Зависимость скорости падения остаточной емкости АКБ в процессе эксплуатации при разных значениях глубины разряда показана на рис. 2, влияние глубины разряда на срок их службы - на рис. 3.

Из анализа графиков, приведенных на рис. 2 и 3, можно сделать вывод, что для обеспечения достаточной длительности работы аккумуляторов (не менее 1500 циклов) не следует допускать глубины разряда более 80\%. С другой стороны, уменьшение глубины разряда приводит к уменьшению доступной для использования энергии, что при заданном значении $\mathrm{P}_{\text {потр }}$ требует увеличения количества АКБ в составе БА.

На практике между этими двумя требованиями обеспечением приемлемой долговечности АКБ и разумным их числом в составе БА - приходится искать компромисс. Возможность такого поиска обеспечивается, в частности, разнообразием технологий, предлагаемых производителями АКБ для фотоэлектрических установок. Так, если для свинцово-кислотных аккумуляторов типов VRLA, AGM VRLA, GEL VRLA рекомендуются значения $\gamma=0,2-0,5$, то при использовании литий-ионных и никель-кадмиевых аккумуляторов, более стойких кглубокому разряду (см. табл. 2), могут быть выбраны и более высокие величины коэффициента разряда. Очевидно, что такое свойство делает АКБ этих типов

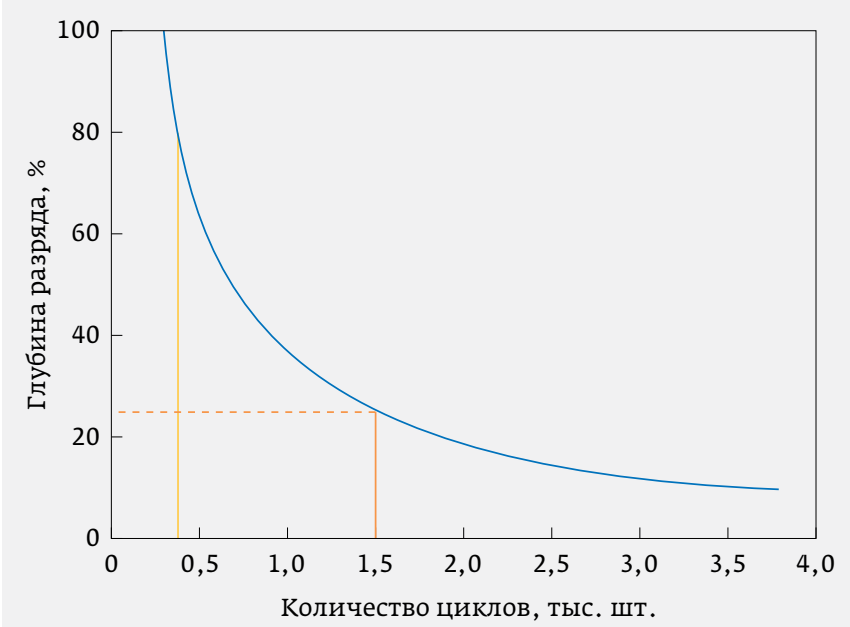

Рис. 3. Зависимость наработки АКБ от глубины разряда

предпочтительными для использования в автономных системах энергоснабжения; к тому же свинцовокислотные аккумуляторы не рекомендуется использовать при отрицательных температурах.

От температуры окружающей среды зависят практически все основные характеристики аккумуляторов. Оптимальной является температура эксплуатации, равная 20-25 C. С уменьшением температуры напряжение АКБ резко падает, ее емкость значительно уменьшается (рис. 4), и в результате ухудшаются условия работы нагрузки, а время функционирования станции в "бессолнечном" режиме сокращается. Последствия повышенных температур в определенном смысле еще неприятнее: если емкость АКБ при возврате к оптимальному значению восстанавливается, то эксплуатация их при высоких

Таблица 2. Глубина разряда различных типов АКБ

\begin{tabular}{lrr} 
Tип батареи & $\begin{array}{r}\text { Допустимый } \\
\text { разряд, } \\
\%\end{array}$ & Рекомендованный \\
VRLA & 70 & разряд, \\
ACM VRLA & 80 & 40 \\
\hline GEL VRLA & 90 & 50 \\
\hline OPZV & 90 & 50 \\
\hline OPZS & 90 & 60 \\
\hline Li-ion & 100 & 60 \\
\hline Ni-Cd & 100 & 80 \\
\hline
\end{tabular}




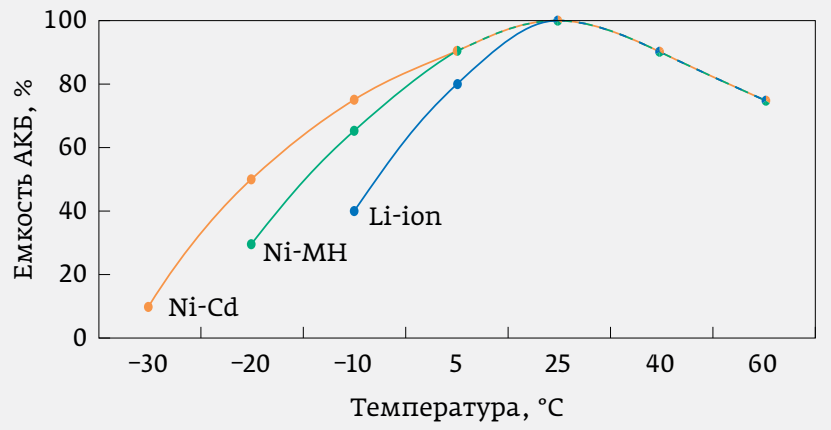

Рис. 4. Зависимость емкости от температуры окружающей среды для типов АКБ, рекомендуемых к применению в составе автономных систем энергоснабжения

температурах приводит к необратимому уменьшению срока их службы (рис. 5).

Температурный коэффициент емкости $\alpha$, введенный в формулу (2), представляет собой множитель, увеличивающий суммарную требуемую емкость АКБ для учета ее падения относительно номинального значения при изменении температуры окружающей среды. Если в проектируемой установке предполагается использовать никелькадмиевые, никель-металлогидридные или литий-ионные аккумуляторы, эксплуатируемые при температурах, близких к оптимальной, то при выборе значения коэффициента $\alpha$ можно использовать данные, приведенные в табл. 3. В общем же случае соответствующая информация должна содержаться в документации производителя АКБ.

В системах автономного энергообеспечения, как правило, применяются АКБ одного типа и емкости [6]. Для получения требуемого напряжения и суммарной емкости БА их объединяют в последовательно-параллельную схему, число отдельных АКБ в которой $\mathrm{N}_{\text {БА }}$ составляет

Таблица 3. Температурный коэффициент аккумуляторной батареи

\begin{tabular}{cc} 
Температура, ${ }^{\circ} \mathrm{C}$ & Коэффициент $\alpha$ \\
26,7 & 1,00 \\
\hline 21,2 & 1,04 \\
\hline 15,6 & 1,11 \\
\hline 10,0 & 1,19 \\
\hline 4,4 & 1,30 \\
\hline$-1,1$ & 1,40 \\
\hline$-6,7$ & 1,59
\end{tabular}

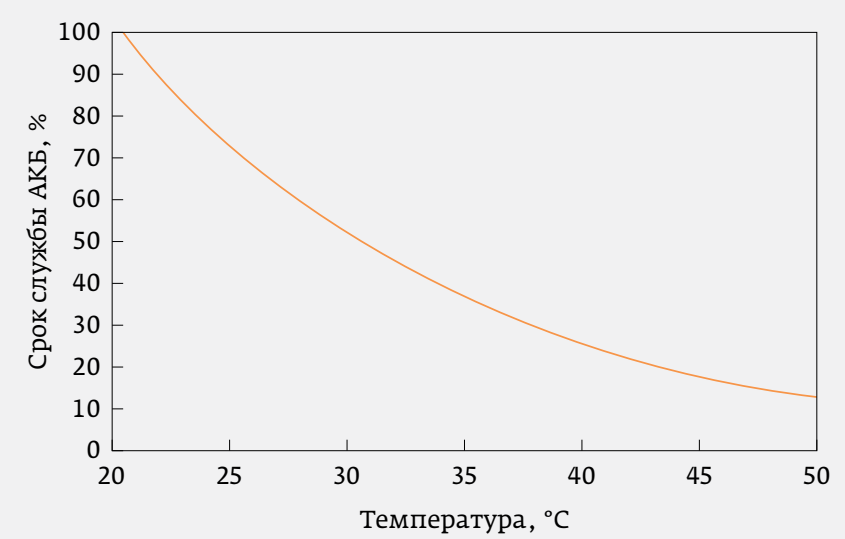

Рис. 5. Зависимость срока службы АКБ от температуры окружающей среды

$$
\mathrm{N}_{\text {БА }}=\mathrm{N}_{\text {пар }} \cdot \mathrm{N}_{\text {посл' }}
$$

где $\mathrm{N}_{\text {пар }}, \mathrm{N}_{\text {посл }}$ - число АКБ, соединенных, соответственно, параллельно и последовательно.

С учетом того, что общая емкость БА $q_{\text {БА }}$ является суммой емкостей отдельных АКБ, а напряжение, создаваемое каждой из параллельных групп, должно равняться входному напряжению инвертора $U_{\text {инв' }}$ выражение (3) можно записать в виде:

$$
\mathrm{N}_{\text {БА }}=\mathrm{N}_{\text {пар }} \cdot \mathrm{N}_{\text {посл }}=\frac{q_{\text {БА }}}{q_{\text {ном }}} \cdot \frac{\mathrm{U}_{\text {инв }}}{\mathrm{U}_{\text {ном }}},
$$

где $q_{\text {ном }}$ - емкость одной АКБ, А·ч; $U_{\text {ном }}$ - напряжение аккумулятора, В.

\section{3. ВЫБОР ТИПА И КОЛИЧЕСТВА СОЛНЕЧНЫХ ПАНЕЛЕЙ}

Размеры предлагаемых производителями солнечных панелей обычно не слишком велики, в пределах 1,5-2,0 м² при мощности до 200-250 Вт. Для достижения нужных значений номинального напряжения и номинальной мощности панели объединяются в последовательные сборки, которые затем коммутируются параллельно, причем в одной сборке следует использовать только однотипные панели [7].

В настоящее время на рынке представлено большое количество разных типов фотоэлектрических панелей. Основными факторами, которые следует учитывать при их выборе, являются площадь панели, номинальное выходное напряжение и тип фотоэлементов.

Электроэнергия, вырабатываемая фотоэлектрическими преобразователями (ФЭП) в течение года, равна

$$
W_{\phi \Pi}=F_{\phi \Pi} \eta_{\Pi} t \sum_{i=1}^{k} N_{\text {сиі }}
$$


где $\mathrm{F}_{\phi п}$ - площадь фотоэлектрических панелей, м²; $\eta_{п}-$ КПД панели; $\mathrm{N}_{\text {сиі }}$ - интенсивность солнечного излучения в $i$-ый период, Вт / м²; $t_{i}$ - продолжительность $i$-го периода, ч; $k$ - число периодов.

Информацию об интенсивности солнечного излучения в месте расположения СэУ, как уже сказано, можно извлечь из базы климатических данных, например, воспользовавшись программой Meteonorm [8]. Можно также получить ее аналитически, путем расчета гарантированного прихода солнечной радиации на горизонтально расположенную приемную площадку [3].

При расчете ФЭП исходными данными, характеризующими нагрузку, является не только номинальная мощность $P_{\text {потр, }}$ но и энергия, потребляемая всеми устройствами, питающимися от станции, в течение суTOK $W_{\text {сут }}($ КВт. ч) [6].

Для покрытия заданной нагрузки должно выполняться условие

$$
W_{\phi п} \geq W_{\text {сут }} \cdot k_{3-p} \cdot 365
$$

где $k_{\text {з-р }}$ - коэффициент, учитывающий потери на зарядкуразрядку АКБ (в системах автономного электроснабжения, как правило, принимается равным 1,2).

Используя выражения (5) и (6), получаем формулу для расчета общей площади ФэП солнечной электростанции

$$
F_{\text {ФП }}=\frac{W_{\text {сут }} \cdot k_{\text {з-р }} \cdot 365}{\eta_{\Pi} \sum_{i=1}^{k} N_{\text {сиі }}},
$$

в которой неизвестной остается одна величина - КПД панели $\eta_{п}$. Эта величина определяется в первую очередь материалом, из которого изготовлен рабочий фотоэлектрический слой солнечной панели.

Сегодня можно говорить о трех поколениях фотоэлектрических элементов: кремниевые моно- и поликристаллические; тонкопленочные (кремниевые, на основе теллурида кадмия и др.); фотосенсибилизованные красителем, органические и неорганические. Полупроводниковые сплавы на основе таких материалов, как индий, галлий и теллур, при преобразовании солнечной энергии в электричество имеют КПД до 40\% и способны работать при температурах до 150 C. Однако In, Ga и Те - это редкие химические элементы и, соответственно, дорогостоящие, поэтому их применение наиболее целесообразно либо в системах с жесткими требованиями к массо-габаритным характеристикам и/или к условиям эксплуатации, либо в установках с концентраторами солнечного излучения.

Другим, более доступным материалам, также свойственны те или иные недостатки с точки зрения использования их в наземных ВИЭ. Поэтому в настоящее время в автономных системах общего назначения наибольшее распространение получили ФЭП на основе кремния. Их монокристаллическая разновидность имеет более высокий КПД, ее характеристики меньше деградируют со временем, такие панели занимают меньшую площадь из расчета на единицу мощности и служат дольше по сравнению с поликристаллическими. Последние, в свою очередь, более эффективны при пасмурной погоде и имеют меньшую стоимость. При повышении температуры окружающей среды электрическая мощность кремниевых панелей снижается на 0,4-0,5\% для каждого градуса выше $25^{\circ} \mathrm{C}$.

Помимо материала фоточувствительного слоя, есть еще много факторов, которые необходимо принять во внимание, определяя облик фотоэлектрического преобразователя для проектируемой солнечной установки.

Так, следует учитывать, что в более крупных панелях более эффективно используется общая площадь и меньше внешних соединений, а значит, выше надежность. Панели напряжением 24 В имеют преимущество перед панелями напряжением 12 В той же мощности; последние имеет смысл выбирать только для систем, у которых 12 В - это рабочее напряжение инвертора. Наконец, при выборе конкретной модели ФЭП следует помнить, что не все они удовлетворяют комплексу требований, предъявляемых к системам автономного энергоснабжения:

- высокая надежность при длительном сроке службы;

- затраты на приобретение, приемлемые с точки зрения сроков окупаемости;

- удобство обслуживания.

Концентраторы солнечного излучения (фоконы, фоклины, линзы Френеля), действие которых основано на собирании лучей Солнца с большой площади и направлении их на малогабаритные ФЭП, применяются и для повышения эффективности обычных солнечных электростанций [9]. При использовании такого рода концентраторов площадь солнечных панелей, необходимая для обеспечения заданной мощности потребления, определяется по графику, приведенному на рис. 6.

После выбора типа панели можно рассчитать количество ФЭП

$$
N_{\Pi}=\frac{F_{\Phi \Pi}}{F_{\Pi}},
$$

где $F_{\text {п }}$ площадь одной панели.

\section{4. ВЫБОР КОНТРОЛЛЕРА ЗАРЯДА}

Для предотвращения преждевременного выхода АКБ из строя в процессе их зарядки/разрядки должны поддерживаться определенные величины токов и напряжений. 


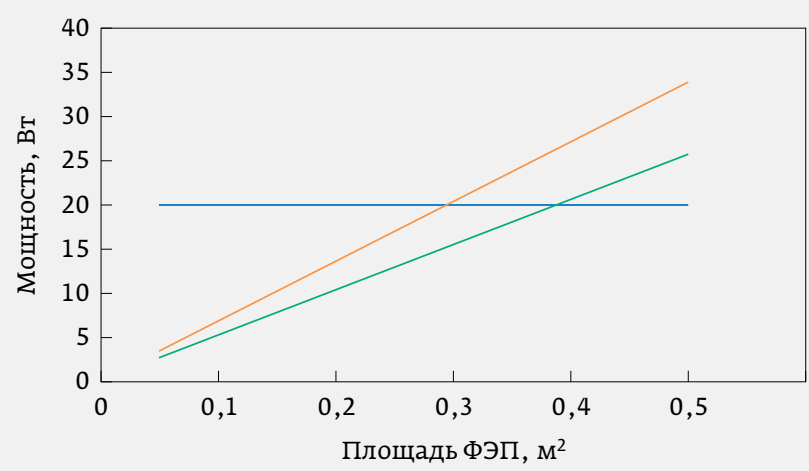

- Требуемая среднесуточная мощность ФэП

- Мощность ФэП с концентратором солнечной энергии

- Мощность ФэП без концентратора солнечной энергии

Рис. 6. Зависимость мощности ФэП от площади солнечных панелей

Эта задача выполняется контроллером заряда. Вторая его задача - поддержание оптимального уровня заряда аккумуляторов при любых режимах работы солнечных панелей: при максимальной емкости АКБ контроллер только компенсирует саморазряд, а при разряде до критического значения - отключает нагрузку.

На сегодняшний день наиболее подходящими для систем автономного энергообеспечения являются МРРТконтроллеры, отслеживающие точку максимальной мощности, что позволяет при любых режимах заряда использовать всю доступную мощность для поддержания предельного напряжения зарядки. В результате удается увеличить эффективность использования солнечной энергии, преобразованной в электричество солнечными панелями, на 10-30\% (зависит от глубины разряда АКБ) по сравнению с установками, эксплуатирующими контроллеры других типов [10].

Выбор контроллера проводится по двум основным параметрам: напряжению на входе и мощности.

Максимальное входное напряжение контроллера должно быть на 20\% выше напряжения холостого хода солнечных модулей, так как на практике возможно превышение этого последнего показателя, вызванное нестабильностью происходящих на Солнце процессов или некорректностью значений, указанных в паспорте панели.

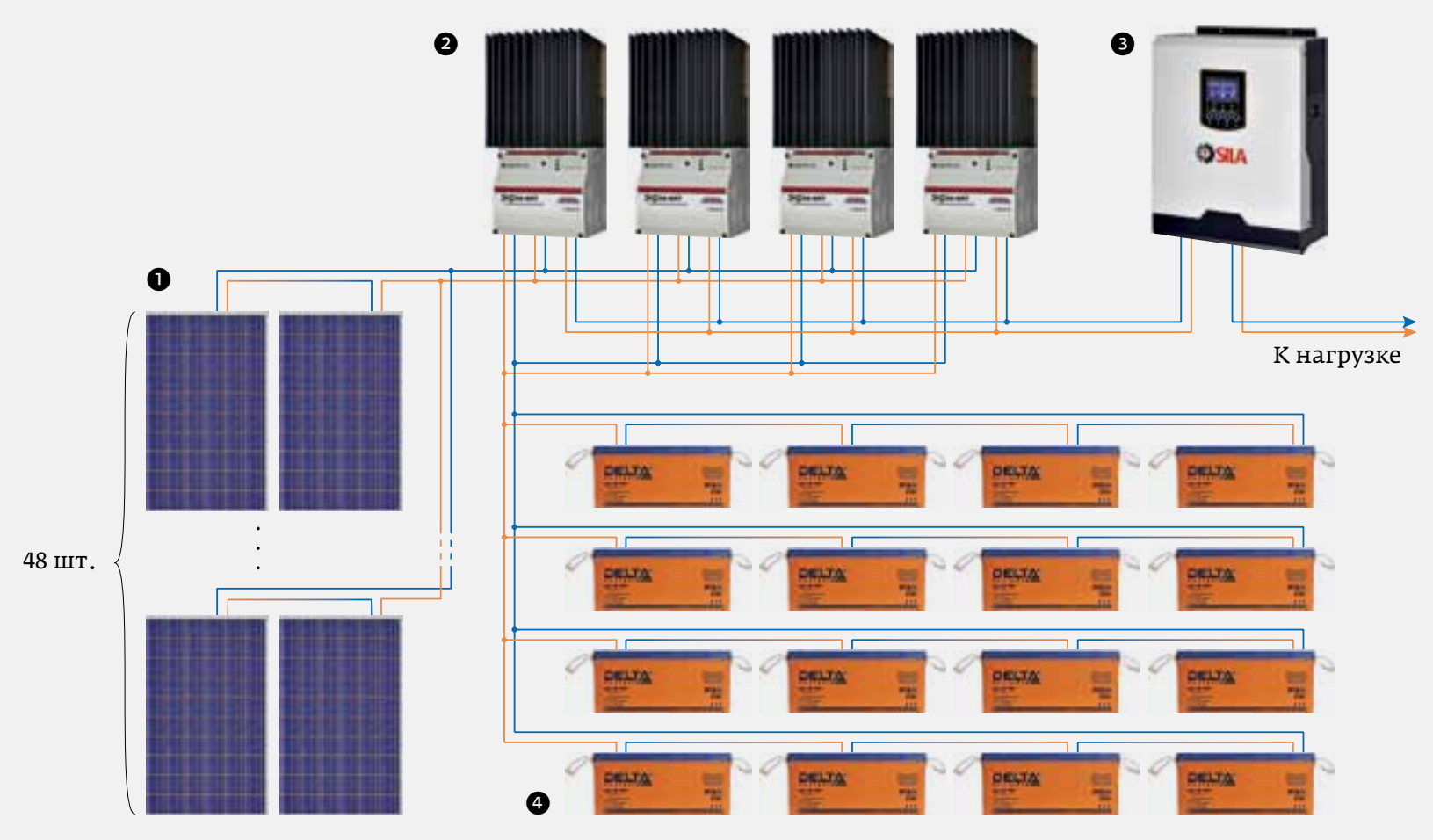

Рис. 7. Компоновочная схема энергетической установки с мощностью потребления 10 кВт: 1 - фотоэлектрический модуль FSM-200 Р (24 В, 200 Вт; в составе установки 48 шт.); 2 - контроллер заряда Morningstar TriStar MPРT 60 (48 B, 50 A; в составе установки 4 шт.); 3 - инвертор SILA PRO $10000 \mathrm{MH}$ (10 kBT); 4 - аккумуляторная батарея ACM (12 В, $200 \mathrm{~A} \cdot$; ; в составе установки 16 шт.) 
Для повышения надежности контроллер должен иметь некоторый запас мощности по сравнению с вырабатываемой ФэП суммарной мощностью, которая рассчитывается по формуле

$$
P_{\Sigma}=I_{K} \cdot U_{c \sigma}
$$

где $I_{\text {к }}$ - выходной ток контроллера, $A_{\text {; }} U_{c б}$ - паспортное значение выходного напряжения ФЭП, В.

Кроме того, желательно, чтобы контроллер заряда обладал дополнительными защитными функциями (от неверной полярности, тока короткого замыкания, перегрузки, перегрева и разрядов атмосферного электричества).

После проведения расчетов и выбора основных компонентов составляется несколько вариантов компоновочной схемы энергетической установки, включающей все основные единицы оборудования, как показано на рис. 7.

Затем рассчитываются допустимые площади поперечного сечения проводов, выбирается вид проводов и соединительных элементов.

\section{5. ВЫБОР ВАРИАНТА ДЛЯ РЕАЛИЗАЦИИ}

На современном рынке представлено множество типов и моделей АКБ, контроллеров, инверторов, солнечных панелей, из которых разработчик, используя результаты расчета по изложенной методике и приведенные рекомендации, может составить несколько вариантов солнечной электростанции, удовлетворяющих его по техническим и эксплуатационным параметрам, а также финансовым возможностям. Для сравнительной экономической оценки и выбора окончательного варианта технического решения в качестве критерия используются суммарные приведенные (дисконтированные) затраты [11], представляющие собой сумму капиталовложений и издержек за срок службы объекта:

$$
3_{\mathrm{d}}^{\Sigma}=\sum_{t=1}^{\mathrm{T}_{\mathrm{pac}}}\left(\mathrm{K}_{\mathrm{t}}+\mathrm{U}_{\mathrm{t}}\right)\left(1-\mathrm{E}_{\mathrm{H}}\right)^{1-t},
$$

где $3_{\mathrm{d}}^{\Sigma}$ - суммарные дисконтированные затраты; $\mathrm{K}_{t}$ - капитальные затраты в год $t ; h_{t}$ - эксплуатационные издержки в год $t$; $E_{\text {н }}$ норма дисконта; $t$ - текущие годы изготовления и эксплуатации станции; $\mathrm{T}_{\text {расч }}-$ расчетный срок службы станции.

Все экономические показатели сравниваемых вариантов определяются в ценах одного временно́го периода по источникам равной достоверности. Стоимостные показатели формируются в соответствии с реально сложившимися отчетными и прогнозируемыми на перспективу ценами на электрооборудование, материалы и монтажные работы.
Изложенная методика проектирования энергетических установок на базе ФЭП позволяет проводить исследование различных составов солнечных энергетических установок, оценивать их эффективность и выбирать подходящий вариант для последующей реализации.

\section{ЛИТЕРАТУРА}

1. Solar Energy. Bloomberg. / Электронный ресурс. https://www.bloomberg.com/quicktake/solar-energy.

2. Виссарионов В.И. Солнечная энергетика.М.: Изд-во МЭИ, 2008.

3. Пчельникова-Гротова О.Н., Мин М.Т. Оценка ресурсов солнечной энергии для снабжения наземных систем обеспечения полетов в республике Мьянма // Труды МАИ 2016. № 91. http://trudymai.ru/published.php? ID=75619.

4. Бушуев В.М., Деминский В.А. Электропитание устройств и систем телекоммуникаций. Учебное пособие для вузов. - М.: Горячая линия - Телеком, 2011.

5. Хрусталев Д.А. Аккумуляторы.- М.: Изумруд, 2003.

6. Бекиров Э.А., Воскресенская С. Н., Химич А. П. Расчет системы автономного энергоснабжения с использованием фотоэлектрических преобразователей. - Симферополь: Национальная академия природоохранного и курортного строительства, 2010.

7. Малинин Н. К., Кузнецова В. А., Виссарионов В. И., Дерюгина Г. В. Солнечная энергетика. Учебное пособие для вузов. ISBN: 978-5-383-00608-5. МЭИ, 2011.

8. Meteonorm Version 7 Handbook / Электронный ресурс http://www.meteonorm.com.

9. Воронин С. М. Нетрадиционные и возобновляемые источники энергии. Курс лекций. - Зерноград: ФГОУ ВПО АЧГАА, 2008.

10. Контроллер заряда для солнечной батареи / Электронный ресурс https://svetuvas.ru/solnechnye-batarei/ kontrollyor-zaryada-solnechnoj-batarei.html

11. Дмитриев А.Н., Ковалев И.Н., Табунщиков Ю.А., Шилкин Н. В. Руководство по оценке эффективности инвестиций в энергосберегающие мероприятия. М.: АВОК-ПРЕСС, 2005 